\title{
Building a Sample Frame of SMEs Using Patent, Search Engine, and Website Data
}

\author{
Sanjay K. Arora ${ }^{1}$, Sarah Kelley ${ }^{2}$, and Sarvothaman Madhavan ${ }^{3}$
}

\begin{abstract}
This research outlines the process of building a sample frame of US SMEs. The method starts with a list of patenting organizations and defines the boundaries of the population and subsequent frame using free to low-cost data sources, including search engines and websites. Generating high-quality data is of key importance throughout the process of building the frame and subsequent data collection; at the same time, there is too much data to curate by hand. Consequently, we turn to machine learning and other computational methods to apply a number of data matching, filtering, and cleaning routines. The results show that it is possible to generate a sample frame of innovative SMEs with reasonable accuracy for use in subsequent research: Our method provides data for $79 \%$ of the frame. We discuss implications for future work for researchers and NSIs alike and contend that the challenges associated with big data collections require not only new skillsets but also a new mode of collaboration.
\end{abstract}

Key words: Sample frame; administrative and big data; machine learning; bias; small and medium-sized enterprises.

\section{Introduction}

Researchers and national statistical institutes (NSIs) are increasingly turning to big data to gather information on individuals, households, firms, and other organizations (Lane 2016). Firm-centric big data sources from the web include websites, social media, email, internet searches, e-commerce channels, administrative databases, machines, and sensors. These sources of online big data complement existing census, survey, and administrative data by adding relevant information on firm behavior, decisioning, networks, and communications, all of which may change in time-sensitive and context-driven ways (Blazquez and Domenech 2018; Einav and Levin 2014). In comparison to primary sources, big data benefits from reduced response burden, lower collections costs, improved timeliness, and broader opportunities for operationalizing different types of variables (Mergel et al. 2016; Buelens et al. 2014). Because of these advantages, the properties of big data for firm-

\footnotetext{
${ }^{1}$ Ernst \& Young, LLP, 1101 New York Ave NW, Washington, D.C., 20005, U.S.A. Email: Sanjay.K. Arora@ey.com

${ }^{2}$ Child Trends, 7315 Wisconsin Avenue, Suite 1200W, Bethesda, MD, 20814, U.S.A. Email: SKelley@ childtrends.org

${ }^{3}$ American Institutes for Research, Washington, D.C., 20007, U.S.A. Email: smadhavan@air.org

Acknowledgments: This work was supported by the US National Science Foundation [grant number 1646773]. Any opinions, findings, and conclusions or recommendations expressed in this material are those of the authors, and do not necessarily reflect the views of the National Science Foundation, Ernst \& Young, LLP, the American Institutes for Research, or Child Trends. The authors wish to thank Jan Youtie and Cyde Tucker for their comments on earlier drafts of this article.
} 
centric data collections are of interest to researchers and NSIs alike. For example, (1) How can a firm's online presence be detected? (2) Can big data provide reliable behavioral measures from which aggregate statistics can be generated? and (3) Which firms, based on an understanding of existing and known sources, are more or less likely to appear online?

Because of its unstructured nature and decentralized governance, however, big data can be a challenge to harvest, pre-process, and analyze. Collecting big data often means accessing sources through disparate "Big Tech" private company infrastructure that may or may not provide data interfaces (Groves and Harris-Kojetin 2017). Additionally, once accessed, working with big data can be a challenge for statisticians, methodologists, and social science researchers expressly because these data are not designed for research (Connelly et al. 2016): Coding to pre-process big data for further use, for example, can be time consuming and complex, and biased representation raises consequential concerns about generalizability to offline contexts. Additionally, operationalizing meaningful measures may require mastery of emerging techniques that are not always prevalent among many statisticians, methodologists, and researchers (Arora et al. 2015).

This article documents a methodological approach to retrieve and process big data from online sources to produce a sample frame of innovative small-to-medium sized enterprises. In our case study, we link patent data from the US Patent and Trademark office to firm websites whose URLs are found through search engine queries. Independently, we collect firm size information to delineate large firms from their small and medium-sized counterparts. Building a sample frame denotes the process of identifying which firm belongs in the sample and associating a firm with a previously unknown URL.

We also devote time to collecting, processing, and assessing parts of a firm website that are most appropriate for further research. As an illustration, we collect only pages related to the firm's management or ownership structure as found in 'about us' pages. In doing so, we show how webpage classification can become a key arbiter in the scope of a web-based data collection effort: Collecting specific pages of interest and operationalizing variables allow researchers and methodologists to (a) evaluate online measures with those found offline in terms of construct validity and measurement error, and (b) eventually replace duplicative questions on surveys once measures become reliable, reproducible, accurate, and of sufficient quality. For example, a future study could focus entirely on identifying the human capital of an establishment (e.g., management structure and educational qualifications), a topic of interest in the new US Annual Business Survey (ABS), which also asks respondents to answer questions about R\&D, innovation, technology, and financing (U.S. Census Bureau 2020a).

Our approach to processing website data comports with the recommendation of making "theoretically informed decisions. . . as to how best to tackle a data set such that it will reveal information which will be of potential interest and is worthy of further research" (Kitchin 2014). While our focus is on a particular sample of innovative SMEs, we contend that our approach could be applied in various research settings, not only in innovation studies but also other fields ranging from education to public health, that is, wherever organizations (loosely defined) are the unit of analysis and an online presence is the norm rather than the exception. The method is also broadly applicable for building a frame list when a register from administrative data is not available or is out-of-date. We describe our method and results with the aim of continuing the ongoing discussion in the statistical and social science communities around using diverse data sources for enterprise-level big data collections and research. 


\section{Literature Review}

According to the U.S. Small Business Administration (2018), there were 30.2 million active small firms in 2015. Small and medium-sized enterprises (SMEs), which in the United States consist of fewer than 500 employees, comprise $99.9 \%$ of all firms in the United States, and they created $65.9 \%$ of net new jobs from 2000 to 2017. In hightechnology industries, which include pharmaceuticals and medicine manufacturing, scientific research and development, and semiconductor manufacturing, 250,865 SMEs represented $98.1 \%$ of employers. Small firms are particularly known for their agility and disruptive potential (Rothwell 1989), and they are often touted, whether mistakenly or not, as the engine of US economic growth (Atkinson and Lind 2018; Birch 1987).

From a public policy standpoint, areas of research, development, and technology commercialization are of notable interest because they contribute disproportionately to economic output, national security, and improvements in quality of life (Lundvall and Borrás 2005). In the present study, the population of interest comprises high-technology firms that patent in three industries, nanotechnology, synthetic biology, and renewable energy. Nanotechnology is a multidisciplinary field of scientific and engineering research focusing on the novel properties of materials that emerge when isolated at the atomic and molecular levels, that is, between 1 and 100 nanometers in length (PCAST 2005). Synthetic biology refers to an emerging field of science that extends or modifies existing behaviors to produce engineered organisms for task-specific purposes (Andrianantoandro et al. 2006). Lastly, renewable energies, according to the U.S. Energy and Information Administration (2018), are derived from sources that are "naturally replenishing but flowlimited." These three industries comprise an appropriate population to study because of their relatively different stages of development, with renewable energy and nanotechnology being more established than synthetic biology (c.f., OECD and The Royal Society 2010; Popp 2016; Toumey, 2009), and because each industry varies in terms of its composition of patent assignees. For example, in comparison to universities, firms hold a larger share of patents in renewable energy and nanotechnology than in synthetic biology (c.f., Munari and Toschi 2014; Popp 2017; Simon 1996; Van Doren et al. 2013).

In the United States, statistics on innovative firms are generated from a variety of sources, but two worth noting in particular are the ABS and Business Enterprise Research and Development (BERD) Survey (U.S. Census Bureau 2020a, 2020b). The ABS, which began in 2017 and initially sampled 850,000 employer businesses, replaced four previous surveys to collect information on business ownership, product and service innovation, patenting behavior, technology methods, marketing, financing, and R\&D (for firms with fewer than ten employees only) (U.S. Census Bureau 2020a). The BERD, in contrast, annually samples approximately 45,000 companies with ten or more employees and focuses entirely on R\&D (U.S. Census Bureau 2020b). The response rate for BERD in 2018 was $74.5 \%$. Other countries maintain similar annual surveys, for example the UK's Business Enterprise Research and Development Survey, which in 2018 enjoyed a response rate of $84 \%$ (U.K. Office for National Statistics. 2020).

In the United States, because of confidentiality and privacy requirements, access to firm micro-data from the federal government by researchers is often more difficult than in other industrialized countries (Einav and Levin 2014). Academic-led firm surveys, in turn, are 
costly and time-intensive to implement and update, and the lag between design and collection to release can be long (Young et al. 2018; Talan 2016). Furthermore, response rates to academic surveys, particularly for small firms, remain low (Baruch and Holtom 2008; Dennis Jr. 2003), leading to concerns about potential bias and the costs borne by respondents and survey administrators alike to ensure sufficiently high response rates (Giesen et al. 2018; Lindič et al. 2012). Yet, in innovation studies and small firm research, the need for data has never been greater given shortened product development cycles, increased competition, unstable external conditions (e.g., the current global pandemic and corresponding policy responses), and the need for firms to 'pivot' between strategies given evolving market realities (see Teece et al. 2016). The rapid cycle of change is a concern for NSIs as well, who are tasked with providing policymakers, businesses, researchers, individuals, other stakeholders with up-to-date statistical indicators. The attraction of big data and open administrative data, therefore, is clear to both NSIs and researchers: access to more data in a timelier fashion with an opportunity to expand the scope of existing, available variables (Groves and Harris-Kojetin 2017).

Across NSIs, the most popular big data sources at the project level include web scraping, scanners, mobile phones, and social media. The most popular topics of study include prices, population/migration, transport/mobility, and geographical/spatial analyses (MacFeely 2019). In Europe, the ESSNet Big Data project, a partnership between Eurostat and 28 national partners, integrates big data into the regular production of official statistics. ESSNet supports a workstream on enterprise characteristics which draws on "web scraping, text mining, and inference techniques for collecting and processing enterprise information" (ESSnet Big Data 2020). Recent research produced in connection with ESSNet has examined job vacancies, pricing, e-commerce capabilities, sustainability reporting, and industry affiliations (Ten Bosch et al. 2018; Berardi et al. 2015; Bruni and Bianchi 2020).

Linking administrative data to other data sets is nothing new in the production of official statistics and in the social sciences (Einav and Levin 2014). For example, numerous studies link scholarly journals and/or patent data to commercial databases (see Lane and Bertuzzi (2011) for examples from science and innovation policy). However, because they are convenience samples, big data sources may suffer from bias because the population under study must be accessible by definition from the source. Identifying problems related to this kind of selectivity bias is an important step in producing valid findings (Beręsewicz et al. 2018; Kaplan et al. 2014). NSIs, for their part as critical producers and stewards of official statistics, must grapple with the question of whether big data are representative and stable enough to use in different policy domains (MacFeely 2019). Comparisons with well-known and trusted data, for example, from surveys and business registries, offer a convenient way to understand and quantify bias (Reimsbach-Kounatze 2015).

\subsection{Sample Frame Generation Using Search Engines to Identify URLs}

A sample frame identifies discrete respondents or observational entities along with their contact information (Särndal et al. 2003). In the present study, patent data identifies the list of patent assignees, but the administrative source does not provide URLs. Consequently, we find website locations online through an alternative channel: search engines. 
Identifying a company website is a type of "navigational" search, which is used to find certain webpages (or homepages) that are assumed to exist (Broder 2002). Navigational queries satisfy the user's information need as soon the right link is found (Lewandowski and Höchstötter 2008). In a 2015 evaluation, Lewandowski found that out of 1,000 navigational queries, Google found the correct page $95.27 \%$ of the time in the top search result, while Microsoft Bing was only successful $76.57 \%$ of the time. However, the author does not report on the success of navigational queries for potential matches within the top $n$ results. It could be that the correct result is often in the top $n$ results, but not always the first result. Graber and Weckman (2002) manually search for nine brand name drugs in eight search engines, constituting 72 searches in total, and find that company websites are listed as the first link for 28 searches, while another 18 appear in the first ten links. This research suggests that search engines can be effective for finding company URLs, but that 'correct' URLs do not always appear as the first result.

A convenient way to obtain URLs is through search engine application program interfaces (APIs). Young et al. (2018) note urban agriculture sites in American cities are underreported in U.S. Department of Agriculture (USDA) lists. The authors conduct exploratory research to determine whether an independent list can be constructed costeffectively using website data. This study is noteworthy because the authors cannot rely on an independent frame for a list of all urban agriculture sites, since urban agriculture in the United States has not been documented in a comprehensive census. The authors consequently employ a series of keywords in Yahoo!'s search API to identify potential sites throughout Baltimore, Maryland, and subsequently undertake several labor-intensive steps to verify positive URLs (and remove incorrect ones).

In other work, two collaborations between private sector aggregators and NSIs in the United Kingdom and the Netherlands define a population of firms by aggregating big data and administrative data to measure the internet and digital economy in the two countries (Oostrom et al. 2016; Nathan et al. 2013). These collaborations are innovative because detecting enterprises through their online presence addresses problems in traditional sources that underestimate the true size of the internet and digital economy.

Wang and Vaughan (2014) note that while most firms have websites, there is variability in how well-represented firms are online due to the amount of resources they put into their web presence. For example, manufacturing firms are less likely to invest in link management, which results in better search engine optimization, and thus their websites may be harder to find. It may also be that the company website does not exist. For example, the company may be out of business, or it may have been acquired. Blazquez et al. (2018) turn to the Wayback Machine, an online archive of websites, to study the relationship between firm survival and website activity. As expected, active websites showing frequent minor or major changes over time highly correlate with active (i.e., not out-of-business) firms, as measured through a business database. In other cases, the firm may be active but not invest in a website: Lin et al. (2011) report that small firms do not always understand and capitalize on the benefits of a strong website presence, in part because of IT-related implementation, evaluation, and management issues.

A growing body of literature employs machine learning (ML) to link populations of firms with their online URLs, in part to sufficiently and reliably identify when no website for a given firm exists. Barcaroli et al. (2016) identify over 80,000 URLs matched to 
existing administrative records held by the Italian National Institute of Statistics. They retrieve candidate URLs from a single search engine query and construct several input features that measure the overlap in data elements from the administrative source and the crawled website, as well as the search result rank. Turning to neural network, random forest, and logistic regression models, they find that predicting correct URL matches yields a test set accuracy of approximately $79-80 \%$ and an $F_{1}$ score (the harmonic mean of precision and recall, a commonly used measure of model performance) of 81-83\% for all three models. In the process, they find that roughly $70 \%$ of firms in the Netherlands own a website. Van Delden et al. (2019a) use a similar approach, albeit with more candidate matches as the result of six separate search engine queries, with Dutch sources of administrative data and URLs derived from search engines. These authors train gaussian naïve bayes, random forest, and support vector machine (SVM) models and find the SVM yields the highest performance in similar ranges reported by Barcaroli et al. (2016). A subsequent report by Van Delden et al. (2019b) reveals even better model performance, between $87 \%$ and $97 \%$, for URL matching.

\subsection{Website Data Collection and Webpage Classification}

'Found data' in the form of big data sources, including websites, are not produced for research purposes and may be very complex to work with (Blazquez and Domenech 2018; Arora et al. 2015), regardless of whether off-the-shelf or open source or custom software is used. Thus, there is a clear need to pre-process and refine the data for further analytical purposes. Computer scientists view the challenge of optimally retrieving select data from a large corpus as an information extraction (IE) problem (Mooney and Bunescu 2005). In one IE variation, Kanani and McCallum (2012) conceive of the resource-bounded information extraction (RBIE) conceptual framework which balances the costs and time spent gathering information with actual information needs. In the RBIE, a query engine retrieves a set of documents, which are filtered before being routed to an IE activity. The IE engine assembles features and uses ML models to determine whether sufficient information has been gathered from the selected documents. If more information is needed, a confidence evaluator determines whether more documents must pass the document filter for analysis, or alternatively, whether a new query must be generated to retrieve a new set of documents. The RBIE is therefore a repeatable, iterative process.

One way of identifying relevant documents is to use a search engine, as described above in detecting firm URLs via navigational queries. Automatically detecting pages through a search engine, and then processing those pages, may identify additional pages for downloading. At the same time, limiting the boundaries of a web crawl may not only save time and resources but also produce better quality data from which to extract features (or in social science parlance, operationalize variables) to satisfy researcher needs (Arora et al. 2015).

Webpage classification is a primary way to filter out irrelevant pages. Qi and Davison (2007) identify two main types of webpage classification: subject and functional. Subject classification associates to the main topic of a page (e.g., R\&D versus products), whereas functional classification speaks to the structural orientation of the page vis-à-vis the broader site, for example, a homepage versus an 'about us' page. They also distinguish 
between two sets of features for classification purposes: (1) on-page features, or variables that are extracted from the focal page to be classified, and (2) features derived from neighbor pages that for example may link to the focal page.

In the Young study (2018) cited above, the authors collect millions of web pages and construct natural language processing (NLP) features to train a naïve Bayes classifier to retain pages relevant to urban agriculture. Glover et al. (2002) find that web classification of pages is most accurate when word features derived from the anchor text of a link (i.e., the highlighted text on a page indicating a hyperlink) - and not the full page text of the focal document - are included in their predictive model, a support vector machine (SVM). This is because anchor text summarizes a page's purpose, for example, as found in navigational menus, and does a better job describing its main topic than the full text itself. In a separate study, Anagnostopoulos et al. (2004) train a probabilistic neural network on word features derived from websites to classify individual pages into one of several ecommerce categories, including product information, orders, terms and conditions, contact and complaints, and after sales support. In their experimental findings, they achieve an accuracy rate of approximately $80 \%$ across all page type categories.

\section{Data and Methods}

This research offers a case study for defining a sample frame using administrative and big data sources for SME research. At a high-level, our method first begins with producing a list of patenting firms (i.e., firm assignees) in three high-technology industries, nanotechnology, synthetic biology, and renewable energy (Steps 1-2, Figure 1). This list

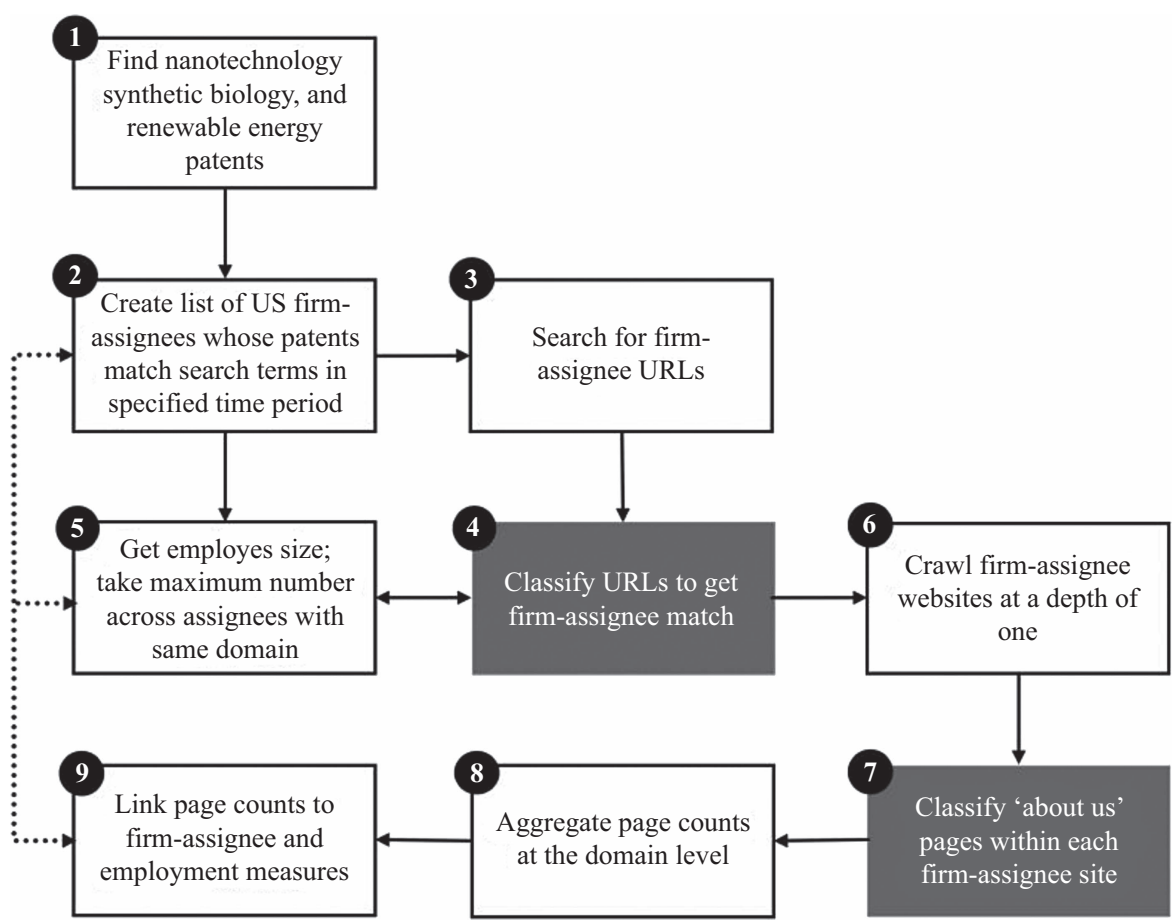

Fig. 1. Modular sampling and data collection process flow. Shaded boxes show machine learning steps. 
derives from administrative data but does not include employment or URL information. URL information is vital for web scraping purposes, and employment figures are needed to remove from the final sample large firms with 500 or more employees.

Next, we (Step 3) search for candidate firm assignee website URLs via a search engine API; (4) apply supervised ML models to predict correct firm-URL matches; (5) gather employment information to determine firm size at the assignee-level; (6) crawl firm assignee websites; (7) apply ML models to predict specific webpages of interest (namely "about us" pages); (8) aggregate page counts at the domain-level; and (9) link website and employment measures with administrative patent data.

Step 1 acts on individual patents, whereas Steps $2-5$ act on firm assignees. A firm assignee is akin to an establishment, or a local unit within an enterprise (National Academies of Sciences, Engineering, and Medicine 2018). Firms, particularly large ones with multiple establishments, typically have one global website. For example, Siemens patents under the names, Siemens Aktiengesellschaft, Siemens Corporation, Siemens Energy, and Siemens Industry in fact, these are disambiguated assignee names (USPTO 2019), but the website associated with each of these assignees is siemens.com. The result is a 1-to- $n$ relationship between website and firm assignee; that is, one website may be linked to multiple firm assignees. Steps 6-7 work on individual webpages, while Step 8 aggregates pages at the domain-level. Step 9 links website data to firm assignee patent and employment measures. The result of the process is a data set at the firm assignee (establishment) level.

The main technology architecture consists of (1) the python machine learning library, scikit-learn (Release 0.20.4) (Pedregosa et al. 2011); (2) Scrapy (https://scrapy.org/) a python open-source web crawling library, integrated with Firefox and Selenium (https:// www.selenium.dev/projects/) a web driver that mimics user browsing behavior without a Firefox user interface; (3) R for data linkage and visualization; (4) MySQL, a relational database, for storing patent data; (5) MongoDB, a document-based database for storing webpage data; (6) Amazon Web Services for cloud computing resources; and (7) GitHub for version control. Code and supporting documentation for this research project corresponding to Steps 3-9 (Figure 1) are open-sourced at https://github.com/euphonic/ EAGER. Code and supporting documentation for Steps 1-2 are open-sourced at https://github.com/euphonic/eager-search-terms. All data were collected in 2018 unless otherwise noted.

\subsection{Producing the Frame List from Patent Data}

PatentsView, a data platform supported by the United States Patent and Trademark Office (USPTO), holds all US patent applications and grants starting from 1976 (USPTO 2019). The platform is primarily intended for research purposes. We use PatentsView to produce a frame list by searching for patents that match three distinct search strategy definitions, one for each industry. We first consider all utility patents granted between 1976 and 2017. In the United States, utility patents are patents for inventions; they comprise approximately $90 \%$ of all granted patents in a given year (USPTO 2020), (There are two other types of patents, design and plant patents, granted in the US.) The keywordbased search definitions derive from Shapira et al. (2013) for renewable energy; Arora et al. 
(2012) for nanotechnology; and Oldham et al. (2012), Raimbault et al. (2016), and Hu and Rousseau (2015) for synthetic biology. The search criteria contain patterns joined by logical ANDs and ORs, as found in the search definitions. For example, for renewable energy, a clause identifying wind power related technologies includes the following terms:

" ( (wind power*) OR (wind energ*) OR (wind farm*) OR (turbin* AND wind*))"

We transform this specification into a python regular expression to execute the search on concatenated patent titles and abstracts. Details on the keyword search implementation along with links to supporting code and data may be found in the online Supplemental material.

The result of the search is a list of boolean flags for each clause in a search definition; we select a patent if it matches any of the search clauses. Then, we apply a time-based filter of utility patents with a grant date of April 2015 to March 2017 to facilitate the likelihood of finding active firm assignees online. Additionally, we retain only those firm assignees that are located in the United States. (Non-firm assignees are identified and subsequently removed through a "thesaurus" of government, university, and hospital patent holders.)

\subsection{Extracting Employment Data from Search Engines}

Employment data are commonly found through business databases and national statistical institutes (e.g., the U.S. Bureau of Labor Statistics). However, proprietary business databases are expensive to access, and NSIs typically provide employment data for each business only to researchers through micro-data access, or when business registers and employment figures belong to the public domain. In the spirit of exploring open access data sources under both cost and time constraints, we turn to publicly accessible employment data via the Google Custom Search API. For each patent assignee in the frame list, we issue two complementary queries and processing approaches, as follows.

The first custom search is bound by one domain, www.linkedin.com. We issue the query ‘ $<$ firm_assignee_name > "see all"” for each patent assignee via Google's Custom Search API. Search results are processed such that the first company profile matching a numeric regular expression is extracted (Box 1). This number is a proxy of employee size as measured by the number of people connections affiliated with the firm-assignee on LinkedIn. This measure is not without error, however. Tambe (2014) finds that LinkedIn, while a valuable source of information, may introduce significant measurement error for employment data; other work in the IT industry shows correlations ranging from 0.61 to 0.81 when comparing LinkedIn measures with external data sources. To address bias from a single source of employment data, that is, from LinkedIn, we turn to a second, complementary procedure.

Box 1. Example of parsing employee information from LinkedIn search result via the Google custom search API.

https://www.linkedin.com/company/angstron-materials See all 29 employees on LinkedIn $\rightarrow \cdot$ See jobs ... Founded in 2007, Angstron Materials is a leading manufacturer of graphene and graphene oxide products. 
The second custom search adds employment data from www.bloomberg. com, www.forbes.com, en.wikipedia.org, and www.hoovers.com. The query issued against these domains is " $<$ firm_assignee_name $>$ number of "employees", again via the Google Custom Search API. Here, a python regular expression extracts numbers from all search results. Because of variation in the search results from these four domains, we implement a fuzzy match algorithm employing term frequency-inverse documentfrequency (see Rajaraman and Ullman 2011) on firm assignee name unigrams to omit certain results that do not appear to be a good match. Further, to reduce measurement error, we take the median value of the resulting list of numbers.

A simple decision rule is applied to take the greater of the two resulting measures if both exist (e.g., the one identified from LinkedIn or the median value from the other sources). Additionally, to handle the issue of multiple assignees belonging to the same enterprise but having different employment numbers, the largest employment figure for all records matching the same website domain is imputed for all assignee instances of that firm.

To evaluate our method of scraping employment data from search engines, we turn to the 2019 Fortune 500 and Global 500 lists capturing the largest United States and global firms, respectively, by revenue. Fortune maintains a number of indicators, including employment, associated with these firms in tabular format. These data are made freely accessible online via Fortune's website (2019a, 2019b). We compare this curated list of employment figures to our scraped method pulling on search engine results and employing the simple decision rule described above.

\subsection{Identifying Firm URLs from Assignee Names Using Search Engines}

To identify firm assignee URLs, first we issue one query for each assignee to Microsoft's Bing Search API to identify possible candidate URLs. We begin with a selected set of 195 assignees. From these 195 records, we identify correct firm assignee name-to-URL matches to obtain labeled data from which to train and validate several ML models, all in the hope of assessing and increasing accuracy of matches.

We store all search results, ignoring common news and social media sites, in MongoDB and derive seven features for modeling: (1) assignee firm name length, as found in PatentsView (positive integer); (2) hit result name length (positive integer); (3) hit URL length (positive integer); (4) matches between assignee name unigrams and hit name unigrams (positive integer); (5) degree to which we think an assignee is public (based on keywords, positive integer); (6) hit rank (e.g., 1 through 10); and (7) degree to which we think an assignee has merged or been acquired (based on keywords, positive integer). We use two types of SVMs, linear and RBF; a Gaussian process; a random forest; and AdaBoost as binary classifiers (Table 1). To assess and compare model performance, we compute each model's accuracy and $F_{1}$ scores, two common measures of performance:

$$
\begin{gathered}
\text { accuracy }=\frac{\text { true positives }+ \text { true negatives }}{\text { total observations }} \\
F_{1}=2 * \frac{\text { precision } * \text { recall }}{\text { precison }+ \text { recall }}
\end{gathered}
$$




\begin{tabular}{|c|c|c|c|c|}
\hline Model & $\begin{array}{l}\text { Used for } \\
\text { URL } \\
\text { classification }\end{array}$ & $\begin{array}{l}\text { Used for } \\
\text { webpage } \\
\text { classification }\end{array}$ & Description & $\begin{array}{l}\text { Scikit-learn } \\
\text { parametrization }\end{array}$ \\
\hline Linear SVM & $x$ & $x$ & $\begin{array}{l}\text { Solves a classification problem by optimizing the } \\
\text { placement of a hyperplane separating vectors of data } \\
\text { points on the border of the plane (Fan et al. 2008) }\end{array}$ & kernel $=$ "linear", $\mathrm{C}=0.025$ \\
\hline RBF SVM & $x$ & $x$ & $\begin{array}{l}\text { This type of non-parametric, kernel-based SVM uses a } \\
\text { radial basis function (RBF) to detect non-linear } \\
\text { boundaries for classification purposes (Cortes and } \\
\text { Vapnik 1995) }\end{array}$ & gamma $=0.001, C=100$ \\
\hline Gaussian process & $\boldsymbol{x}$ & & $\begin{array}{l}\text { This too is a non-parametric, kernel-based model. It } \\
\text { assumes a gaussian process as the prior, and the } \\
\text { posterior is approximated using a Laplace } \\
\text { approximation for classification (Williams and } \\
\text { Rasmussen 2006) }\end{array}$ & kernel $=1.0 * \operatorname{RBF}(1.0)$ \\
\hline Decision tree & $\chi$ & $x$ & $\begin{array}{l}\text { Creates a tree-like representation with simple if-then rules } \\
\text { to bin data points into groups. Optimizes rules based on } \\
\text { an impurity function calculated at each node in the tree } \\
\text { (Safavian and Landgrebe 1991) }\end{array}$ & max_depth $=5$ \\
\hline Adaboost & $\chi$ & $\boldsymbol{x}$ & $\begin{array}{l}\text { Ensemble meta-classifier that takes multiple weak learners } \\
\text { (decision trees) and uses sample weights to improve } \\
\text { training, and eventually, classification outcomes (Hastie } \\
\text { et al. 2009) }\end{array}$ & $\begin{array}{l}\text { n_estimators }=50, \\
\quad \text { learning_rate }=1\end{array}$ \\
\hline $\begin{array}{l}\text { Multi-perceptron } \\
\text { neural network }\end{array}$ & & $x$ & $\begin{array}{l}\text { Maps in linear and non-linear ways a number of input } \\
\text { features to output classes via any positive number of } \\
\text { hidden layers; training occurs via backpropagation } \\
\text { (Kingma and Ba 2014) }\end{array}$ & $\begin{array}{l}\text { alpha }=0.1, \text { hidden_layer } \\
\text { _sizes: }=[100], \text { max_iter } \\
\quad=50, \text { solver }=\text { 'adam' }\end{array}$ \\
\hline
\end{tabular}


The $\mathrm{F}_{1}$ score is the harmonic mean of precision and recall. Precision is defined as the ratio of true predicted positives to all predicted positives (whether true or false) in a binary classification problem. Recall refers to the ratio of true predicted positives to all labeled positives.

Next, we implement a simple majority vote algorithm to aggregate the models' collective confidence of a possible URL match for a given firm assignee $f$ :

$$
\text { top vote urls } \in \operatorname{argmax}_{\text {url }}\left(\sum_{i}^{m} y_{i}\right)
$$

where $i$ iterates over each model $m$ and $y_{i}$ is a given model's prediction, either 0 or 1 . If top vote urls $_{f}$ returns a set, a tie is broken by selecting the highest ranked URL in the initial search results. The resulting list of firm-assignee to URL matches is manually inspected to assess and improve on data quality before crawling firm webpages. Alternatives to the above specification (Equation 3) could include dynamic classifier or ensemble selection methods, which have been shown to outperform static combination approaches such as majority voting (Cruz et al. 2018).

\subsection{Website Crawling and Classifying Web Pages}

After identifying URLs, we begin the crawling process. The first step involves crawling all pages for a firm domain with a depth of one; that is, the crawler traverses and stores data from each firm's homepages and for all pages linked to from the homepages. Although we could focus on harvesting and processing data from entire websites, planned future work entails analyzing SME content likely to be isolated in firms' homepages and 'about us' pages. Thus, we turn to webpage classification models to filter out extraneous, non- 'about us' pages.

We first identify candidate 'about us' pages through a python regular expression matching terms, such as 'about', 'company', 'corporate', 'who we are', 'vision', 'profile', 'history', 'values', 'strategy', and 'story'. We search for these terms on homepages in URL path fragments, as well as the text surrounding URLs. Homepages themselves are also considered potential 'about us' pages. Next, from a firm-assignee random sample, we hand label 1,455 pages $(13.2 \%)$ of all candidate 'about us' pages $(11,030)$ as to whether they are deemed true 'about us' pages. There are 389, or $26.7 \%$, true 'about us' pages out of 1,455 pages. The 'about us' label incorporates a broad set of pages having to do with the firm's mission, culture/ethos, primary capabilities, key technologies, history, and organizational structure. This excludes corporate governance pages that speak to corporate social responsibility and sustainability; investor materials for public companies; locations, which are particularly meaningful for multi-national corporations; and news pages.

To train and validate ML models on the labeled data, we produce seven features (Figure 2):

1. The number of candidate 'about us' pages at depth one within the website; this feature is site specific and measures how many potential 'about us' pages might exist on a given site, per the identification strategy defined above.

2. Whether a given page is an 'about us' page as opposed to a homepage. A homepage may contain 'about us' text, for example on a very small website or a single-page site. 
3. The proportion of sentences on a page to the number of sentences on all candidate 'about us' pages. For a potential 'about us' page, what percentage of sentences on all candidate 'about us' pages is found on this page?

4. Unigrams derived from descriptor text around the focal page's inbound link, for example, from a homepage. What words would a viewer see before clicking on a link to a candidate 'about us' page?

5. URL path fragment unigrams. Following the domain name, what textual elements are found on the URL path?

6. Page title unigram fragments. Which words, not including stop words, appear in the candidate 'about us' page's HTML title text?

7. Unigrams from a page's top-level header text. Which words, not including stop words, appear in the candidate 'about us' page's header text?

We also specify bi- and tri-grams where appropriate but because evaluation metrics deteriorate significantly with their inclusion in the models, we do not report on them further below. A five-fold cross validation approach is used with accuracy averaged across each fold to report training performance.

\subsection{Measuring Bias}

Using administrative data to produce a frame list upon which to map representation in big data sources (e.g., websites and social media) provides one way to assess bias in big data sources. We assess bias to determine which firm assignees may be under- or overrepresented in the frame since patenting firms without a website are omitted from the data collection. To perform this analysis, we first link the firm-assignees from the patent search to employment and aggregated website data.

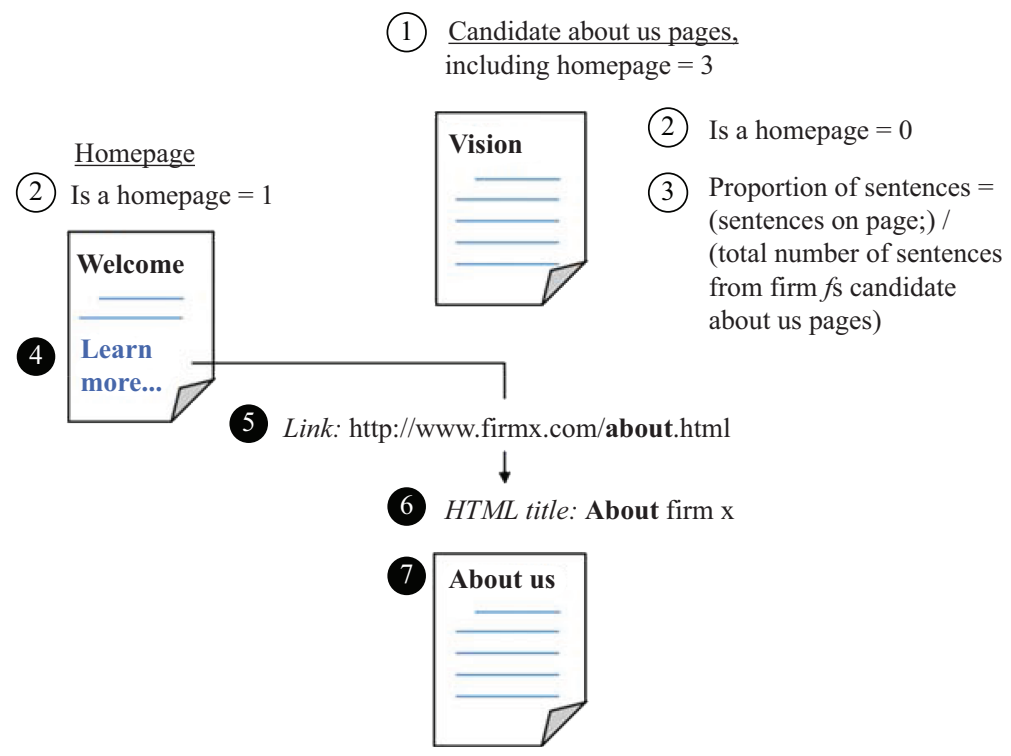

Fig. 2. Seven count features (white circles) and text-derived features (black circles) used for webpage classification modeling. Text unigrams are transformed into count features for modeling. See text for descriptions. 
We measure bias using logistic regression. Our two dichotomous dependent variables of interest include (1) whether a firm URL was found and (2) whether website content was successfully crawled. Explanatory variables common to both models include (a) the first year the firm-assignee patented; (b) number of total patents belonging to the assignee, logged; (c) mean number of assignees with which the firm co-patented; (d) mean inventors associated with the assignee's patents; (e) the number of industries, rather than a particular industry (synthetic biology, nanotechnology, and/or renewable energy), in which an assignee patents; (f) the length of the firm assignee's name; and (g) number of employees, logged.

\section{Results}

The empirical results examine the accuracy of the URL identification and webpage classification methods (Subsection 4.2), as well as our approach to gathering employment Figures (Subsection 4.3). We also assess any bias in the sample frame as a result of firm assignees not maintaining a website presence and having no website data (Subsection 4.4). The results show that out of 1,487 US-based patent assignees in the sample, 1,381 have employment data, with 770 identified as having fewer than 500 employees. In total, we collect website data on 607 (79\%) of patenting SMEs in our sample, with smaller firms less likely to be represented with website data than larger firms, on average. Table 2 shows the number of records captured at each step of the research design.

\subsection{Patent Search Results to Identify Firm-Assignees}

As shown in Table 3, the results of the patent search yield 12,714 non-unique utility patents across the three industries, with more patents in nanotechnology than in renewable energy or synthetic biology. Most patents are in nanotechnology, followed by renewable

Table 2. Number of observations after each stage of data collection.

\begin{tabular}{llrr}
\hline $\begin{array}{l}\text { Stage } \\
\text { (Figure 1) }\end{array}$ & \multicolumn{1}{c}{$\begin{array}{c}\text { Description } \\
\end{array}$} & \multicolumn{1}{c}{ Observation type } & $\begin{array}{c}\text { Observations } \\
\text { remaining } \\
\text { after stage }\end{array}$ \\
\hline 1 & Find industry patents & Individual patents & 12,714 \\
2 & Create sample frame list & Firm-assignees & 1,487 \\
3,4 & Find and classify URLs & Firm-assignee to matched URLs & 1,288 \\
5 & Get employment & Firm-assignees with employment & 1,381 \\
& information & and matched patent data & 770 \\
$6-7$ & Get and classify webpages & Candidate about us webpages & 11,030 \\
8 & Aggregate website data & Firm-assignees with website data & 1,186 \\
9 & Link SME assignee patent & SME firm-assignees with & 607 \\
& data with employment & employment and website data & \\
& and website data & & \\
\hline
\end{tabular}

Note: These varying numbers can be attributed to the type of observation (e.g., patent, firm-assignee, or webpage) analyzed at each step of the sample frame creation and data collection process, as well as corresponding data quality and accessibility issues (e.g., whether an assignee URL was found or whether the website was successfully crawled). Subsections 4.1-4.4 present the detailed results underlying this table. 
Table 3. Matching patent and firm assignee counts.

\begin{tabular}{lrrc}
\hline & $\begin{array}{r}\text { Renewable } \\
\text { energy }\end{array}$ & $\begin{array}{r}\text { Synthetic } \\
\text { biology }\end{array}$ & Nanotechnology \\
\hline Utility patent matching search strategy & 2,436 & 1,694 & 8,584 \\
Patents with US assignee information & 1,576 & 1,277 & 6,981 \\
$\begin{array}{l}\text { Number of unique assignees (within } \\
\quad \text { industry) }\end{array}$ & 607 & 573 & 1,099 \\
$\begin{array}{l}\text { Firm assignees (not including government, } \\
\quad \text { university, and hospital) across all } \\
\text { three industries }\end{array}$ & & 1,487 & \\
\hline
\end{tabular}

energy and synthetic biology. Since firm assignees patent in multiple industries, the number of unique assignees across industries is not additive.

\subsection{URL Identification and Webpage Classification Experimental Findings}

To identify website URLs from a list of assignee names, we use the Microsoft Bing Search API. Recall the API returns candidate URLs, that is, possible matches. We train and evaluate five ML models (Table 1) on 154 labeled firm-URL matches and 963 labeled non-matches from the 195 pilot firms. (A non-match is a search result that is not the firm's homepage.) Manual inspection of the first 'hit' in the results list from a pilot of 195 firms show an error rate of approximately $18 \%$. In other words, $18 \%$ of the first hit URLs were not correct.

The overall accuracy is very high for all models; thus, no grid search for optimal hyperparameters was performed: Accuracy scores using group cross-validation (with three splits) for linear SVM, RBF SVM, gaussian process, decision tree, and AdaBoost models were $0.973,0.974,0.976,0.976$, and 0.979 , respectively. The $F_{1}$ scores were $0.906,0.908$, $0.913,0.916$, and 0.924 , respectively.

In the final prediction step, using the five trained models, we predict URL matches for both SMEs and large firms. Of these predictions, 986 are consistent across the top five performing models (Table 4). Interestingly, for the assignee-URL matches consistently

Table 4. Firm URL match prediction results.

\begin{tabular}{lcrrc}
\hline $\begin{array}{l}\text { Predictions } \\
\text { received }\end{array}$ & $\begin{array}{c}\text { Number of firms } \\
\text { in prediction class }\end{array}$ & $\begin{array}{c}\text { Retained } \\
\text { matches }\end{array}$ & Precision & $\begin{array}{c}\text { Average search result } \\
\text { rank of proposed match }\end{array}$ \\
\hline 0 & 165 & 30 & $18.2 \%$ & 1.55 \\
1 & 106 & 71 & $67.0 \%$ & 2.14 \\
2 & 81 & 57 & $70.4 \%$ & 1.30 \\
3 & 65 & 65 & $100.0 \%$ & 1.29 \\
4 & 84 & 81 & $96.4 \%$ & 1.06 \\
5 & 986 & 984 & $99.8 \%$ & 1.00 \\
Total & 1,487 & 1,288 & $86.6 \%$ & 1.18 \\
\hline
\end{tabular}

Note: A matched URL is defined as the candidate URL with the most predictions from the five ML models. We assess the overall quality/accuracy of the top matches using manual review ('retained matches'). Performance of the model prediction scheme declines with two or fewer models agreeing on the top match. If a matched URL receives zero predictions, this means no model predicts the candidate URL as a correct match URL. In this case, by default, we identify the first ranked hit in the search results after removing certain known sites, for example, Facebook and LinkedIn, from the candidate pool. 
predicted across all five models, all but two (99.8\%) were correct. Similar findings are seen for matches with three or four predictions; that is, the precision is quite high, nearing $100 \%$. However, when no more than two models agree on a match, precision declines appreciably, with final match rates of $70.4 \%, 67 \%$, and $18.2 \%$ for the two, one, and zero prediction classes, respectively. These findings suggest that if a firm can be found online, search engines (specifically Microsoft Bing) identify the right URL most of the time: The precision of the majority voting approach is $86.6 \%$. Furthermore, the method is particularly adept at finding false positives of top ranked search results that may warrant careful inspection by other data quality improvement methods, whether manual or automated. This means that in practice, if manual review is used, a researcher could spend his or her time inspecting and/or cleaning URL matches identified by two or fewer models, thus reducing the number of manually reviewed records by more than $75 \%$ (here 352 distinct assignees).

The supervised ML method for webpage classification closely follows the URL identification method; that is, we identify five candidate models and measure their accuracy and $\mathrm{F}_{1}$ scores with a cross-validation scheme. However, these models as a whole perform worse than the URL identification ones, so here we pay special attention to feature engineering and the performance of different model specifications with and without certain features.

Cross-validation accuracy rates for each class of model with different feature specifications are shown in Figure 3. The results show the top five performing models all achieve accuracy rates between 0.732 and 0.742 for specifications with count-only features; this increases to 0.732 to 0.877 with only text-based features. With all features, the best performer is the MLP neural network with an accuracy of 0.888 . Using grid search for tuning

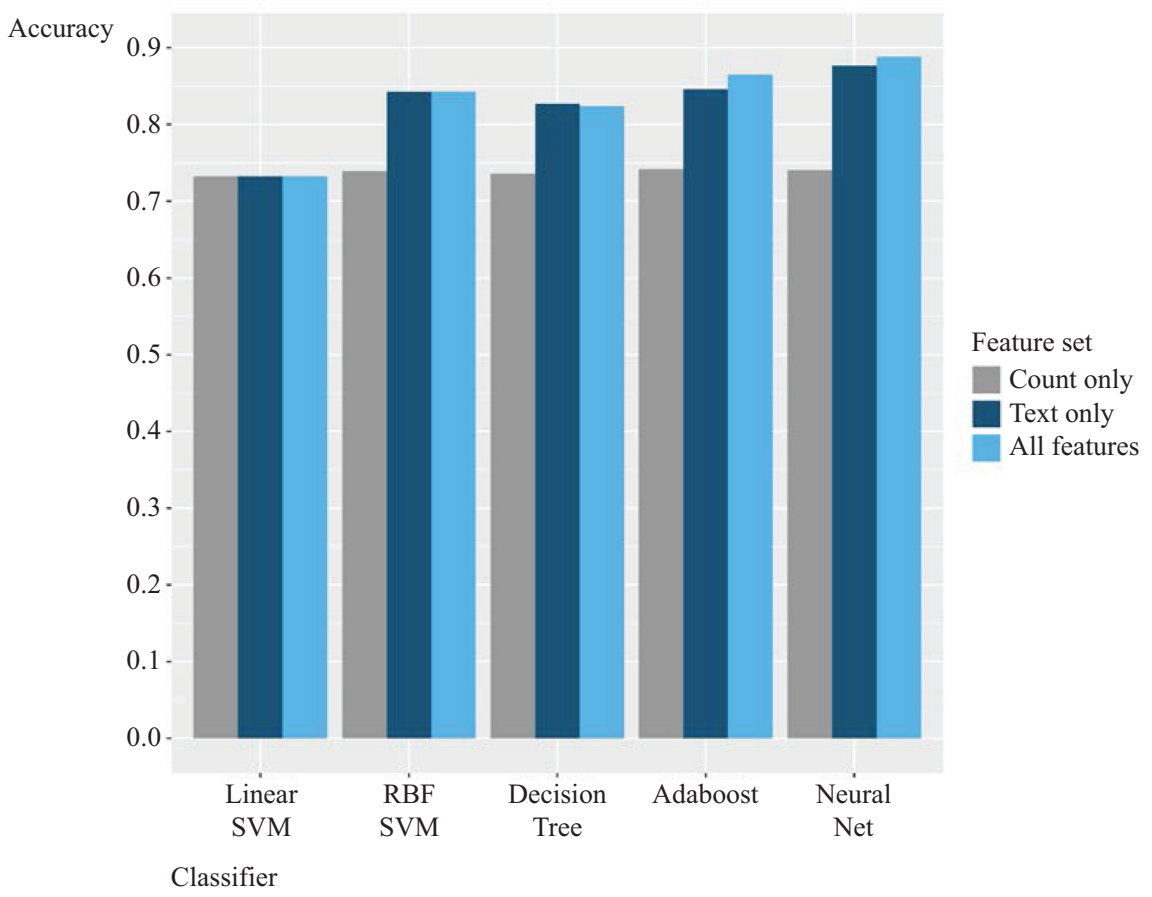

Fig. 3. Webpage classification model results for 'about us' pages. 
hyperparameters, the fully specified neural network model with alpha $=0.1$, one hidden layer size $=100$, and maximum iterations $=50$, using the Adam solver in a $20 \%$ out-ofsample test set, produces a final evaluation accuracy of 0.869 . This means that approximately $87 \%$ of the pages in the test set are correctly classified by the final neural network as either being an 'about us' page of interest or not. The corresponding $F_{1}$ score is 0.76 .

Manual examination of pages incorrectly classified shows that, in some cases, the model mistakenly predicts 'about us' pages that incorporate multiple types of content. For example, some firms, specifically small ones with single page websites, maintain 'about us' content on their homepages. In other cases, some firms combine information about the firm with their management teams on a single page. The models as a whole are often not able to distinguish between these mixed cases because they are trained at the page level, not at the paragraph level. To maintain representation of all firms in the data set without predicted 'about us' pages, we add 101 homepages to the list of predicted 'about us' pages.

\subsection{Findings by Firm Size}

LinkedIn data were found for 1,359 of the 1,487 assignees (91.4\%), while data from the second search (www.bloomberg.com, www.forbes.com, en.wikipedia.org, and www.hoovers.com) offer a median measure for just 651 assignees (43.8\%). The mean and median of employees identified on LinkedIn are 4,756 and 56, respectively. The mean and median from the second search are 20,455 and 2,708, respectively. This suggests that the second search identifies the largest of firm-assignees that should be excluded from the final SME sample.

To examine the accuracy of our method, we compare Fortune 500 and Global 500 firms with the assignee employment figures gathered from the two search queries. The results show that 111 of these Fortune and Global 500 firms are in the study frame. The Pearson's correlation coefficient on $\log$ scraped employees and log Fortune employees is 0.73 $(\mathrm{t}=11.271, \mathrm{df}=109, \mathrm{p}$-value $=0.0)$. Figure 4 provides a plot of these two variables indicating a strong, positive relationship. This correlation is well within the range reported by other work showing correlations between official employment figures and scraped LinkedIn measures ranging from 0.61 to 0.81 in the IT industry (Tambe 2014). Unfortunately, we are unable to access a secondary employment database from which to evaluate SME employment figures. Consequently, this should be a topic of future research.

Table 5 shows descriptive differences between SMEs and large firms. (Note some firms patent across two or three different industries.) Of noteworthy significance, SMEs are less likely to patent than large firms (2.73 average patents in comparison to 8.53 in the three focal industries). SMEs show an average first year of patenting of 2004, while large firms on average patent first in 1994. This comports with a general consensus in the literature that large firms often enjoy higher patenting rates than small firms because large firms (a) are more likely to maintain organizational capabilities in patenting, in general; (b) are more able to enforce their patent portfolio from infringement; and (a) are more likely to patent in incremental process innovations vis-à-vis product innovations with broader scope and longer R\&D timelines (Hicks and Hegde 2005; Demirel and Mazzucato 2012; Coughlin 2006; Lanjouw and Schankerman 2004).

The relationship between number of employees and number of web pages is interesting because it provides a way to assess the amount of content one can expect to collect, parse, 


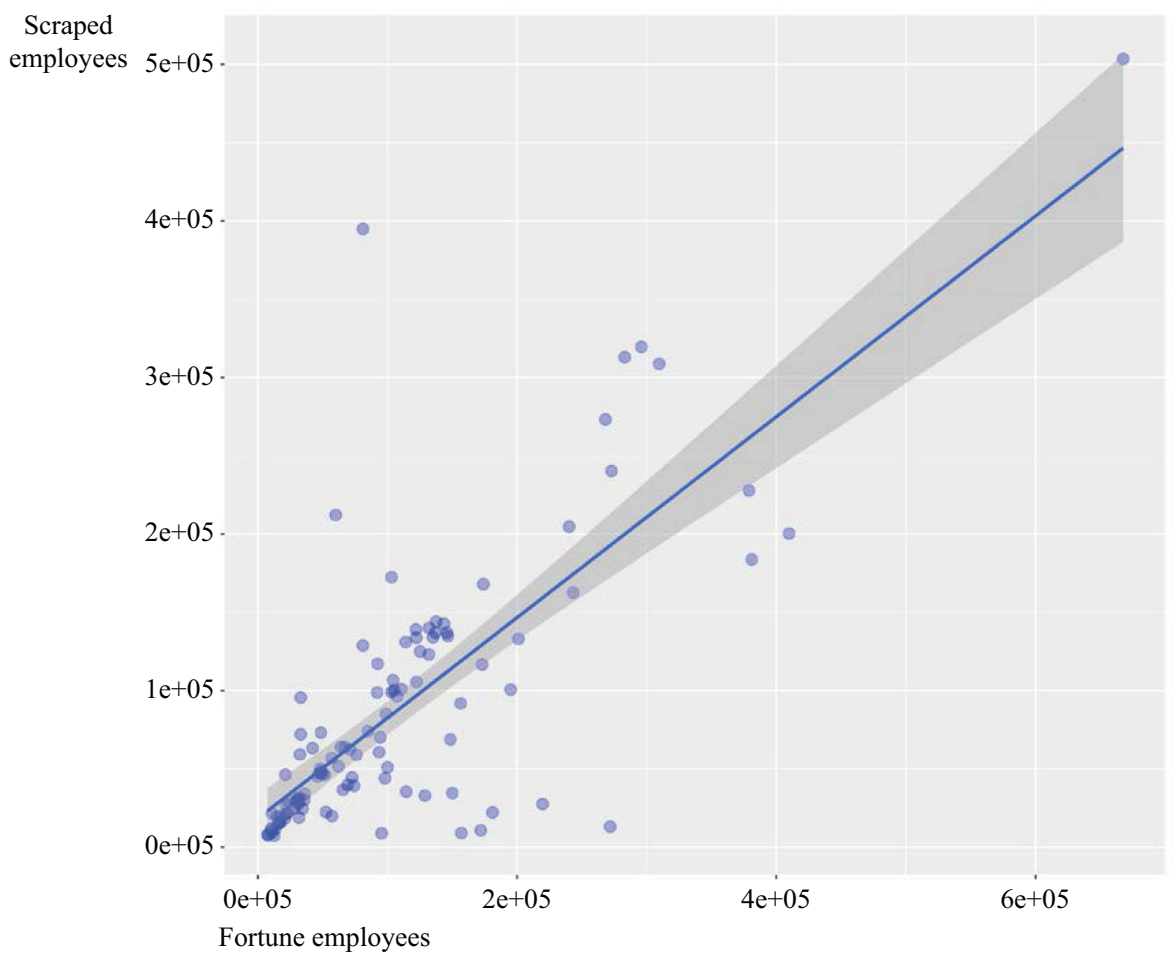

Fig. 4. Fortune 500 and Global 500 employment figures vs. scraped employment figures. $n=111$ (large) firms.

and analyze with studies of varying sample sizes, and with firms of varying sizes. Figures $5 \mathrm{a}$ and $5 \mathrm{~b}$ depict scatterplots with number of pages and employment size by SME, as well as a trend line fitted through local polynomial regression. While both graphs show a noisy relationship between firm size and number of webpages, the webpage classification method decreases the number of pages by website, regardless of firm size. This is an important result, indicating that it is possible to sift through voluminous websites to hone

Table 5. Descriptive comparison of patent and website indicators for SMEs and large firms. SMEs have fewer than 500 employees. $n=1,381$ firms with employment data.

SMEs

Average number of employees

Average year of first patent

Average number of patents

In the three industries

Overall

Average number of inventors

In the three industries

Overall

Average number of assignees

In the three industries

Overall
Large firms 


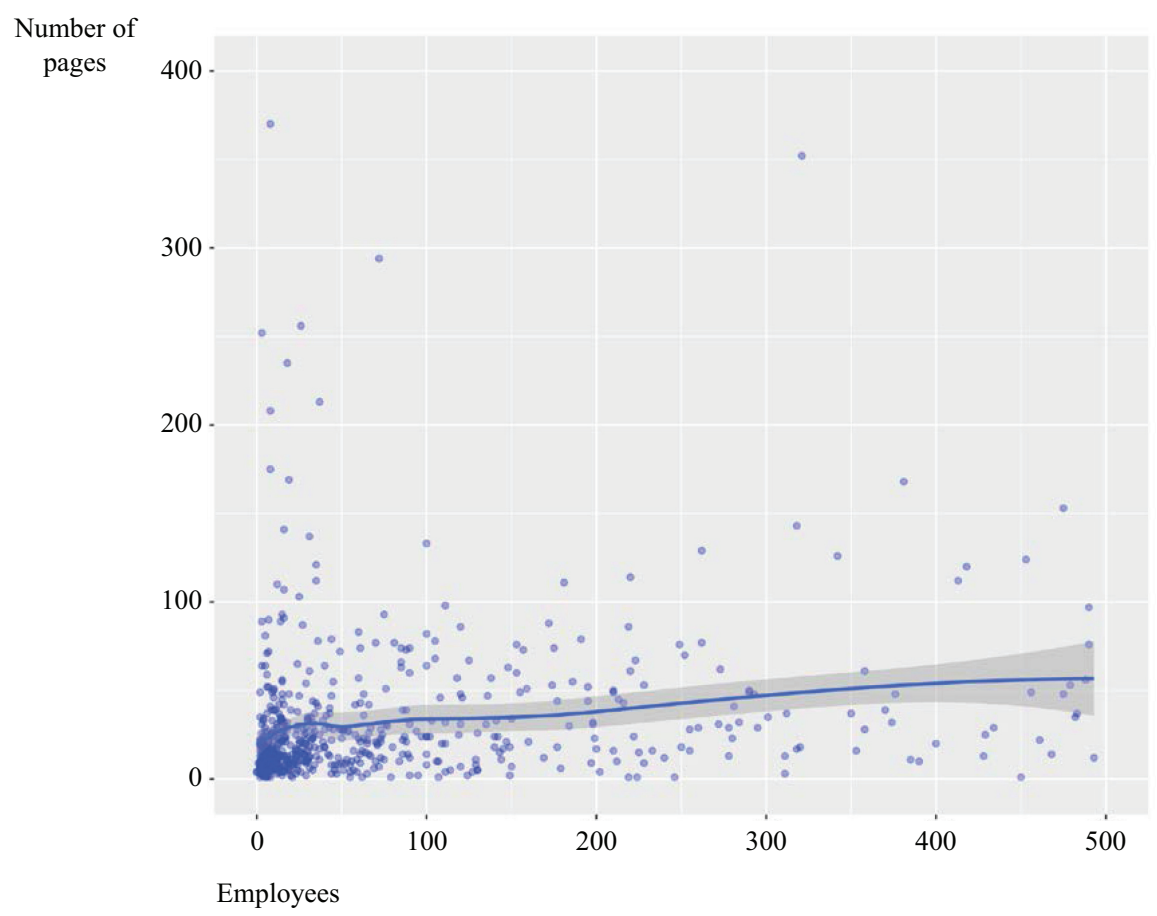

Fig. 5a. Scatterplot of employees and number of pages. $n=607$ SMEs.

in on pages that should identify comparable, non-confounding content. From here, we can then produce reliable and meaningful measures out of the unstructured text. In the present study, for example, we focus on 'about us' pages that are likely to highlight content related to human capital, including the structure and educational qualifications of the firm's management. If conducting a survey, we could employ named entity recognition (NER) and regular expression matching to identify contact information of specific employees in different roles (e.g., CEO or CFO). Other webpage classification schemes may be employed in related studies depending on the research context. For example, only product and/or e-commerce pages may be important if the measures of interest include new product development and how the firm goes about marketing those products.

\subsection{Assessing Bias in the Convenience Sample}

A primary concern with using big data sources is selection bias, and this can be characterized as either source-specific or unit-specific (Beręsewicz et al. 2018). Sourcespecific big data error is endemic to electronic platforms, and here we consider two types, the first of which is geographic. We demarcate the population of SMEs as based in the US, which enjoys high internet penetration (Pew 2018). A second type of source-specific bias could stem from industry-level differences. Upon analysis, however, we see only small variations in industry with respect to online presence, with $84.4 \%, 85.5 \%$, and $86.5 \%$ of renewable energy, nanotechnology, and synthetic biology firm assignees, respectively, having a website. Because the United States maintains high internet penetration, because 


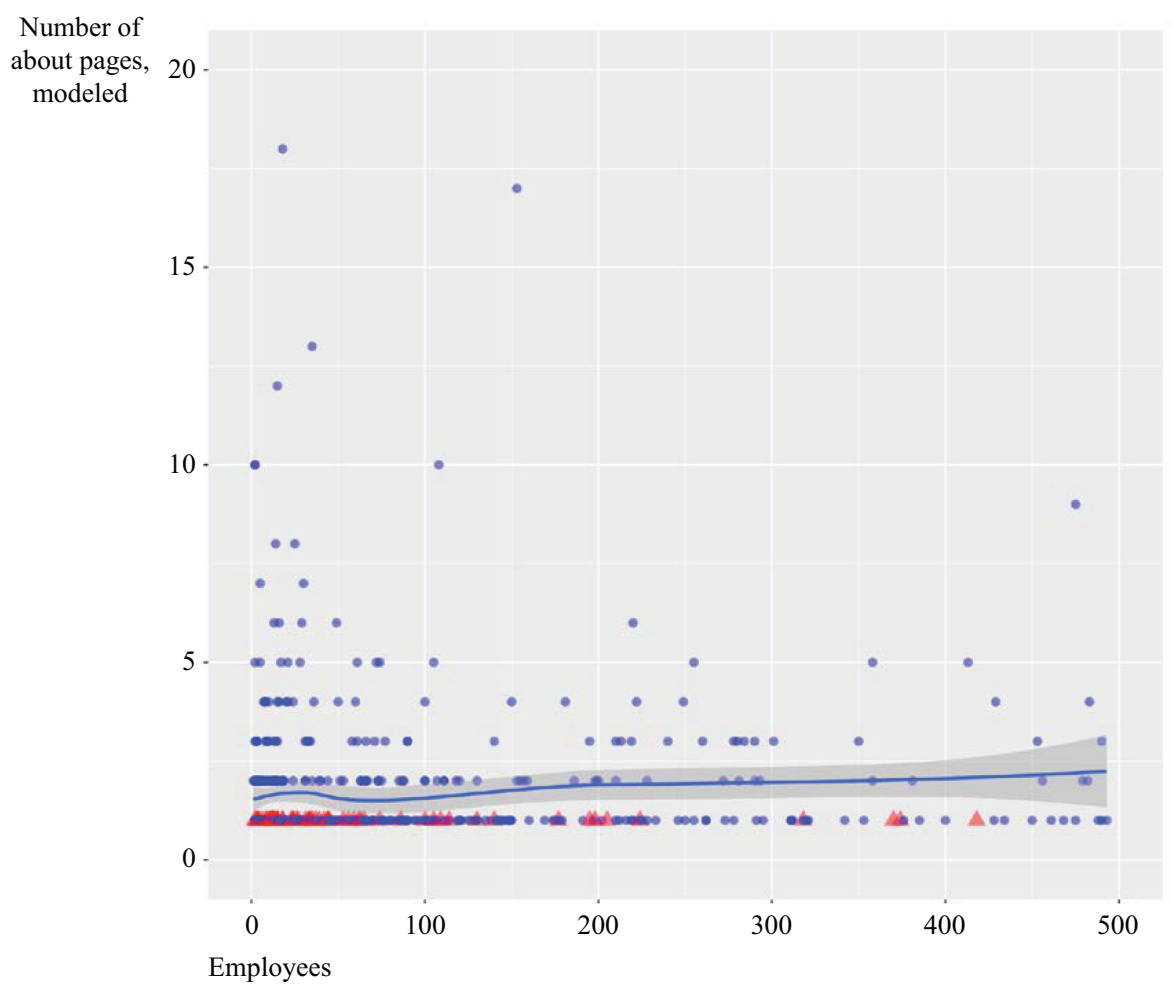

Fig. 5b. Scatterplot of employees and predicted about us pages.

Note: Firms for which there is no predicted 'about us' page are represented with triangles; homepages are used instead in such cases. $\mathrm{n}=596$ SMEs.

there are no significant industry differences, and because simple websites are neither difficult nor costly to implement, we view the decision as to whether to have a website as an individual firm choice. That is, we assess unit-specific error. However, it may also be the case that businesses without websites are no longer active (Blazquez et al. 2018). While we do not have the ability to fully distinguish between these potential sources of bias, we can characterize the nature of missing observations using a combination of employment and patent indicators, which are common to both missing and non-missing observations.

Table 6 presents the results of the two logit models, M1 and M2. In the first model, the odds of being able to identify a URL increase by a factor of 2.10 with each additional industry the assignee patents in, while the percent change in odds of identifying a URL increases by $51 \%$ as employee size increases $e$-fold, holding the other variables constant. This suggests that larger and more diverse establishments (assignees) are more likely to be 'found' on search engines than smaller and less diverse establishments. Logged number of patents also appears to be marginally important, and indeed all three variables, logged patents, logged employees, and number of industries are positively correlated (see Table 7 in the Appendix, Section 6).

At the same time, these three variables are negatively correlated with first year patenting, which may be considered a proxy for firm age. We see no clear evidence that younger firms are more likely to have a website than older firms, but this may be a domain-specific 
Table 6. Logistic regression results on missing observations with odds-ratios reported.

\begin{tabular}{|c|c|c|c|c|c|c|}
\hline & $\begin{array}{l}\text { Has url } \\
\text { (M1) }\end{array}$ & $\begin{array}{l}\text { std } \\
\text { err }\end{array}$ & $\mathrm{p}>|\mathrm{z}|$ & $\begin{array}{l}\text { Has website } \\
\text { content (M2) }\end{array}$ & std err & $\mathrm{p}>|\mathrm{z}|$ \\
\hline Firm name length & 0.98 & 0.01 & 0.02 & 0.99 & 0.01 & 0.13 \\
\hline First year patented & 1.01 & 0.01 & 0.23 & 1.00 & 0.01 & 0.62 \\
\hline Mean assignees & 0.81 & 0.43 & 0.68 & 0.49 & 0.19 & 0.07 \\
\hline Mean inventors & 0.98 & 0.08 & 0.84 & 0.97 & 0.06 & 0.68 \\
\hline $\begin{array}{l}\text { Number of patents, } \\
\text { logged }\end{array}$ & 0.91 & 0.06 & 0.13 & 0.93 & 0.05 & 0.16 \\
\hline $\begin{array}{l}\text { Number of employees, } \\
\text { logged }\end{array}$ & 1.51 & 0.07 & 0.00 & 1.14 & 0.03 & 0.00 \\
\hline Number of industries & 2.10 & 0.62 & 0.01 & 1.22 & 0.21 & 0.25 \\
\hline Constant & 0.00 & 0.00 & 0.24 & 8248.76 & 117317.10 & 0.53 \\
\hline $\begin{array}{l}\text { Number of } \\
\text { observations }\end{array}$ & 1,376 & & & 1,376 & & \\
\hline LR $\operatorname{chi} 2(7)$ & 128.24 & & & 30.27 & & \\
\hline Prob $>$ chi 2 & 0.00 & & & 0.00 & & \\
\hline
\end{tabular}

outcome of the high-technology focus of the sample. It may very well be that older firms in non-science and technology industries are less likely to have a website.

Lastly, M1 shows that for every additional character in an assignee's name, there is a $2 \%$ decrease in odds of finding a URL via the Bing search API. This is a somewhat surprising result since one might posit that longer firm names may help search engines produce less ambiguous query results. Compared to M1, M2 shows similar results overall, but many p-values increase. Two notable exceptions are (1) mean assignees, which shows a marginally negative relationship with likelihood of having a website, and (2) logged number of employees, which retains its importance.

\section{Discussion and Conclusion}

We approach the challenge of sample frame generation using administrative and big data sources in the case-study context of small firm innovation. Rather than using commercial data sources, which can be expensive (Flanegin et al. 2011), the project employs entirely open source and/or low-cost data sources and software: We build our frame list with administrative patent data and turn to search engines to identify firm assignee URLs and employment data. The URL matching test results show a precision of $86.6 \%$ on the full set of 1,487 assignees. Then, we capture firm assignee webpages in two distinct ways, that is, all pages at a depth of one, as well as candidate about us pages identified on a firm assignee's homepage. The webpage classification method produces a smaller subset of pages of interest, thereby reducing large variations in the number of pages at the firm assignee level to a more consistent and manageable number. Our evaluation of different web page classification models produced a top-performing neural network, achieving an accuracy of $87 \%$. Recall that Anagnostopoulos et al. (2004) classify firm web pages and achieve an accuracy rate of approximately $80 \%$ using SVM.

Our analysis of bias suggests that larger establishments are easier to 'find' online than smaller ones in terms of website presence - and that these large establishment websites 
are more likely to be successfully crawled. Additionally, firm assignees that patent in more than one industry are more likely to have found URLs. Overall, while smaller firms appear to be underrepresented online vis-à-vis their larger and more diverse counterparts, $79 \%$ of patenting firms in the sample with fewer than 500 employees have websites. In an age of declining survey response rates, such a finding is encouraging.

\subsection{Limitations and Future Work}

We see a number of important opportunities for future work, three of which closely associate with limitations. First, patent data reflect only a portion of the inventive activity of firms. Trade secrets, shortened lead time cycles, and complementary sales and services are three other common ways firms protect intellectual property (Cohen et al. 2000). Small firms choose not to patent because $R \& D$ processes are informal, there are risks associated with the loss of intellectual property after disclosure, and/or the cost of patenting is too high. Thus, while we define our population in terms of patenting (inventive) small firms, not all small firms patent, and consequently, our results may not generalize to other similar populations (most notably, highly innovative SMEs that do not patent). Future work here could examine other frame lists deriving from non-patent data (e.g., the small firm US government database, SAM.gov) to explore relationships between website indicators and other administrative or survey data sources.

Second, data quality is a key concern with any big dataset not originally produced for research or with statistical purposes in mind. This current research takes a number of steps to ensure sufficient data quality, for example, running ML models on URL search results to remove false positives, canvassing multiple sources of employment data, and culling only those webpages that may be of interest for follow-on study in SME innovation research.

Further validation processes could also be pursued to catch false positives, for example, by determining whether the content of a website matches the general technological orientation of a firm's patent portfolio. If there is a discrepancy between patenting and website activity, then the obtained URL may not appropriately match the assignee after all. Similarly, future work could also do more to reduce the false negative rate of missing URLs, for example, URLs for firm-assignees that should have been found but were not. Research by Van Delden et al. (2019a, 2019b) has shown that a multitude of query types drawing on more than the firm name can be effective in identifying correct URL matches from search engines. For example, searching for name plus address or name plus street name could identify correct URL matches if the n-model prediction scheme introduced in Subsection 3.1 does not produce at least three positive model predictions. If performed in an iterative fashion, the process of examining whether sufficient information has been retrieved could be implemented in alignment with the RBIE framework (Kanani and McCallum 2012), which accounts for constraints and generates new queries for document collection if a threshold for information retrieval is not met. Further, as noted in Oostrom et al. (2016), many small firms, particularly sole proprietors, maintain an online presence on Facebook or other similar social media websites, if at all. For those firms without websites, crawling social media sources may provide at least some representation for those firms not included in the present study's sample frame. This study omits social media pages from its definition of enterprise websites. 
Third, we are able to collect website and employment data on approximately $79 \%$ of the SMEs in the sample. This is much higher than most response rates received from academic surveys and in line with the US BERD survey, but possibly lower than coverage found in for-fee data sets from commercial vendors and other compulsory surveys administered by NSIs. However, website measures must be derived with a specific intent on quality and accuracy. Survey instruments, interview protocols, and other means of primary data collection benefit from a clearer line between construct development and variable operationalization. Thus, deriving meaningful and accurate variables for analysis is a fundamental and far-reaching area for future work.

Outside of science and innovation policy, there are other areas of domain-specific social science research that may benefit from this method more broadly. For example, as noted above, this work follows Young et al. (2018), who build a frame list of urban agriculture sites using a search engine, targeted keywords, and a mixed-method validation method. Similar data collections for frame generation could be pursued in other domains, ranging from education, for example, identifying rosters of teachers on school websites, to public health, for example, assessing the specialization of practitioners in metropolitan areas. The substantive domain area will dictate how websites (and/or other big data sources) will be processed, in terms of classifying certain types of webpages for further variable operationalization and analysis.

\subsection{Conclusion}

Because one of the key challenges in using large-scale administrative and big data sources is the amount of up-front time needed to clean and pre-process the data for further analysis, researchers should expect to spend considerable time - that is, more time than with research designs using primary collections - getting to the analysis stage. Fortunately, there is ample opportunity to build open source codebases and communities around using free to low-cost data sources, such as websites and search engines, for research in science and innovation policy and beyond. Examples of open science tools include the Dataverse project (King 2007), Zenodo (Sicilia et al. 2017), and the Center for Open Science's SHARE project (Sullivan et al. 2019). Under such arrangements, researchers need not be experts in each phase of the big data collection, cleaning, and analysis process, but can instead rely on reusable assets in much the same way that software engineers do to build new functionality by relying on existing modules. There is an increasing need for social science researchers to become more adept at handling large volumes of data, understanding how to leverage existing codebases, and writing new software that can be made available to the larger research community. 
Table 7. Correlations between variables in bias analysis.

\begin{tabular}{|c|c|c|c|c|c|c|c|c|c|}
\hline & $\begin{array}{c}\text { Has } \\
\text { url }\end{array}$ & $\begin{array}{c}\text { Has } \\
\text { website } \\
\text { content }\end{array}$ & $\begin{array}{l}\text { Firm } \\
\text { name } \\
\text { length }\end{array}$ & $\begin{array}{c}\text { First } \\
\text { year } \\
\text { patented }\end{array}$ & $\begin{array}{c}\text { Mean } \\
\text { assignees }\end{array}$ & $\begin{array}{c}\text { Mean } \\
\text { inventors }\end{array}$ & $\begin{array}{c}\text { Number of } \\
\text { patents, } \\
\text { logged }\end{array}$ & $\begin{array}{c}\text { Number of } \\
\text { employees, } \\
\text { logged }\end{array}$ & $\begin{array}{c}\text { Number of } \\
\text { industries }\end{array}$ \\
\hline Has url & 1.00 & & & & & & & & \\
\hline Has website content & 0.75 & 1.00 & & & & & & & \\
\hline Firm name length & -0.05 & -0.04 & 1.00 & & & & & & \\
\hline First year patented & -0.06 & -0.05 & 0.18 & 1.00 & & & & & \\
\hline Mean inventors & 0.03 & -0.01 & 0.00 & 0.01 & 0.25 & 1.00 & & & \\
\hline Number of patents, logged & 0.12 & 0.06 & 0.01 & -0.65 & 0.00 & 0.09 & 1.00 & & \\
\hline Number of employees, logged & 0.26 & 0.12 & 0.01 & -0.42 & 0.06 & 0.10 & 0.64 & 1.00 & \\
\hline Number of industries & 0.09 & 0.04 & 0.03 & -0.22 & 0.02 & 0.08 & 0.41 & 0.26 & 1.00 \\
\hline
\end{tabular}




\section{References}

Anagnostopoulos, I., C. Anagnostopoulos, V. Loumos, and E. Kayafas. 2004. "Classifying Web Pages Employing a Probabilistic Neural Network." IEE Proceedings - Software 151 (3): 139. DOI: https://doi.org/10.1049/ip-sen:20040121.

Andrianantoandro, E., S. Basu, D.K. Karig, and R. Weiss. 2006. "Synthetic Biology: New Engineering Rules for An Emerging Discipline.” Molecular Systems Biology 2. DOI: https://doi.org/10.1038/msb4100073.

Arora, S.K., Y. Li, J. Youtie, and P. Shapira. 2015. "Using the Wayback Machine to Mine Websites in the Social Sciences: A Methodological Resource." Journal of the Association for Information Science and Technology. DOI: https://doi.org/ 10.1002/asi.23503.

Arora, S.K., A.L. Porter, J. Youtie, and P. Shapira. 2012. "Capturing New Developments in An Emerging Technology: An Updated Search Strategy for Identifying Nanotechnology Research Outputs.” Scientometrics 95 (1): 351-70. DOI: https://doi. org/10.1007/s11192-012-0903-6.

Atkinson, R.D., and M. Lind. 2018. Big is Beautiful: Debunking the Myth of Small Business. MIT Press.

Barcaroli, G., M. Scannapieco, and D. Summa. 2016. "On the Use of Internet As a Data Source for Official Statistics: A Strategy for Identifying Enterprises on the Web." Rivista Italiana Di Economia, Demografia E Statistica 70 (4): 20-41.

Baruch, Y., and B.C. Holtom. 2008. "Survey Response Rate Levels and Trends in Organizational Research." Human Relations 61 (8): 1139-60. DOI: https://doi.org/ 10.1177/0018726708094863.

Berardi, G., A. Esuli, T. Fagni, and F. Sebastiani. 2015. "Classifying Websites by Industry Sector." In Proceedings of the 30th Annual ACM Symposium on Applied Computing SAC '15, 1053-59. New York, New York, USA: ACM Press. DOI: https://doi.org/ 10.1145/2695664.2695722.

Beręsewicz, M., R. Lehtonen, F. Reis, L. Di Consiglio, and M. Karlberg. 2018. “An Overview of Methods for Treating Selectivity in Big Data Sources.” Eurostat Statistical Working Papers. Luxembourg. DOI: https://doi.org/10.2785/312232 (accessed July 2020).

Birch, D.G.W. 1987. Job Creation in America: How Our Smallest Companies Put the Most People to Work. University of Illinois at Urbana-Champaign.

Blazquez, D., and J. Domenech. 2018. "Big Data Sources and Methods for Social and Economic Analyses." Technological Forecasting and Social Change 130 (May): 99-113. DOI: https://doi.org/10.1016/j.techfore.2017.07.027.

Blazquez, D., J. Domenech, and A. Debón. 2018. "Do Corporate Websites' Changes Reflect Firms' Survival?” Online Information Review 42 (6): 956-70. DOI: https://doi. org/10.1108/OIR-11-2016-0321.

Broder, A. 2002. “A Taxonomy of Web Search.” ACM SIGIR Forum 36 (2): 3-10. DOI: https://doi.org/10.1145/792550.792552.

Bruni, R., and G. Bianchi. 2020. "Website Categorization: A Formal Approach and Robustness Analysis in the Case of e-Commerce Detection." Expert Systems With Applications 142: 113001. DOI: https://doi.org/10.1016/j.eswa.2019.113001.

Buelens, B., P. Daas, J. Burger, M. Puts, and J. Van Den Brakel. 2014. "Selectivity of Big Data.” Available at: https://www.researchgate.net/profile/Bart_Buelens/publica- 
tion/261436243_Selectivity_of_Big_data/links/00b49539806fa06b08000000/Selectivity-of-Big-data.pdf.

Cohen, W.M., R.R. Nelson, and J.P. Walsh. 2000. "Protecting Their Intellectual Assets: Appropriability Conditions and Why U.S. Manufacturing Firms Patent (or Not)." 7552. Available at: http://www.nber.org/papers/w7552 (accessed February 2020).

Connelly, R., C.J. Playford, V. Gayle, and C. Dibben. 2016. "The Role of Administrative Data in the Big Data Revolution in Social Science Research." Social Science Research 59: 1-12. DOI: https://doi.org/10.1016/j.ssresearch.2016.04.015.

Cortes, C., and V. Vapnik. 1995. "Support-Vector Networks." Machine Learning 20 (3): 273-97. DOI: https://doi.org/10.1007/BF00994018.

Coughlin, S.M. 2006. "Is the Patent Paradox a Result a Large Firm PerspectiveDifferential Value of Small Firm Patents Over Time Explains the Patent Paradox." Santa Clara Computer \& High Tech. LJ 23: 371. Available at: https://digitalcommons.law.scu.edu/cgi/viewcontent.cgi?referer=https://scholar.google.com/\&httpsredir=1\&article $=1429 \&$ context $=$ chtlj (accessed March 2019).

Cruz, R.M.O., L.G. Hafemann, R. Sabourin, and G.D.C. Cavalcanti. 2018. "DESlib: A Dynamic Ensemble Selection Library in Python.” Available at: http://arxiv.org/abs/ 1802.04967 (accessed March 2020).

Demirel, P., and M. Mazzucato. 2012. "Innovation and Firm Growth: Is R\&D Worth It?" Industry \& Innovation 19 (1): 45-62. DOI: https://doi.org/10.1080/13662716. 2012.649057.

Dennis Jr., W.J. 2003. "Raising Response Rates in Mail Surveys of Small Business Owners: Results of An Experiment." Journal of Small Business Management 41 (3): 278-95. DOI: https://doi.org/10.1111/1540-627X.00082.

Einav, L., and J. Levin. 2014. "Economics in the Age of Big Data." Science 346 (6210): 1243089-1243089. DOI: https://doi.org/10.1126/science.1243089.

ESSnet Big Data. 2020. "WPC Enterprise Characteristics - ESSnet Big Data." Available at: https://webgate.ec.europa.eu/fpfis/mwikis/essnetbigdata/index.php/WPC_Enterprise_characteristics (accessed March 2020).

Fan, R.-E., K.-W. Chang, C.-J. Hsieh, X.-R. Wang, and C.-J. Lin. 2008. "LIBLINEAR: A Library for Large Linear Classification." Journal of Machine Learning Research 9: 1871-74. DOI: https://dl.acm.org/doi/pdf/10.5555/1390681.1442794.

Flanegin, F., S. Racic, and D. Rudd. 2011. "Accuracy and Cost of U.S. Financial Data." Journal of Applied Business Research (JABR) 25 (6). DOI: https://doi.org/10.19030/jabr.v25i6.994.

Fortune. 2019a. "Fortune 500 | Fortune." Available at: https://fortune.com/fortune500/ (accessed March 2020).

Fortune. 2019b. "Fortune 500 | Fortune." Available at: https://fortune.com/fortune500/ (accessed March 2020).

Giesen, D., M. Vella, C.F. Brady, P. Brown, D. Ravindra, and A. Vaasen-Otten. 2018. "Response Burden Management for Establishment Surveys at Four National Statistical Institutes." Journal of Official Statistics 34 (2): 397-418. DOI: https://doi.org/10.2478/ jos-2018-0018.

Glover, E.J, K. Tsioutsiouliklis, S. Lawrence, D.M. Pennock, and G.W. Flake. 2002. "Using Web Structure for Classifying and Describing Web Pages." In Proceedings of 
the Eleventh International Conference on World Wide Web - WWW '02, 562. New York, New York, USA: ACM Press. DOI: https://doi.org/10.1145/511446.511520.

Graber, M.A., and M. Weckmann. 2002. "Pharmaceutical Company Internet Sites As Sources of Information About Antidepressant Medications.” CNS Drugs 16 (6): 419-23. DOI: https://doi.org/10.2165/00023210-200216060-00005.

Groves, R.M., and B.A. Harris-Kojetin, Eds. 2017. "Innovations in Federal Statistics." Washington, D.C.: National Academies Press. DOI: https://doi.org/10.17226/24652.

Hastie, T., S. Rosset, J. Zhu, and H. Zou. 2009. "Multi-Class AdaBoost." Statistics and Its Interface 2 (3): 349-60. DOI: https://doi.org/10.4310/SII.2009.v2.n3.a8.

Hicks, D., and D. Hegde. 2005. "Highly Innovative Small Firms in the Markets for Technology." Research Policy 34 (5): 703-16. DOI: https://doi.org/10.1016/j.respol. 2005.03.008.

Hu, X., and R. Rousseau. 2015. "From a Word to a World: The Current Situation in the Interdisciplinary Field of Synthetic Biology.” PeerJ 3 (January): E728. DOI: https://doi. org/10.7717/peerj.728.

Kanani, P.H, and A.K. McCallum. 2012. "Selecting Actions for Resource-Bounded Information Extraction Using Reinforcement Learning." In Proceedings of the Fifth ACM International Conference on Web Search and Data Mining - WSDM '12, 253. New York, New York, USA: ACM Press. DOI: https://doi.org/10.1145/2124295.21 24328.

Kaplan, R.M., D.A. Chambers, and R.E. Glasgow. 2014. "Big Data and Large Sample Size: A Cautionary Note on the Potential for Bias." Clinical and Translational Science 7 (4): 342-46. DOI: https://doi.org/10.1111/cts.12178.

King, G. 2007. "An Introduction to the Dataverse Network As An Infrastructure for Data Sharing." Sociological Methods \& Research 36 (2): 173-99. DOI: https://doi.org/ 10.1177/0049124107306660.

Kingma, D.P., and J. Ba. 2014. “Adam: A Method for Stochastic Optimization.” ArXiv Preprint ArXiv:1412.6980. Available at: http://arxiv.org/abs/1412.6980 (accessed February 2020).

Kitchin, R. 2014. "Big Data, New Epistemologies and Paradigm Shifts.” Big Data \& Society 1 (1): 205395171452848. DOI: https://doi.org/10.1177/2053951714528481.

Lane, J. 2016. "Big Data for Public Policy: The Quadruple Helix." Journal of Policy Analysis and Management 35 (3): 708-15. DOI: https://doi.org/10.1002/pam.21921.

Lane, J. And S. Bertuzzi. 2011. "Measuring the Results of Science Investments." Science 331 (6018): 678-80. DOI: https://doi.org/10.1126/science.1201865.

Lanjouw, J.O., and M. Schankerman. 2004. "Protecting Intellectual Property Rights: Are Small Firms Handicapped?" The Journal of Law and Economics 47 (1): 45-74. DOI: https://doi.org/10.1086/380476.

Lewandowski, D., and N. Höchstötter. 2008. "Web Searching: A Quality Measurement Perspective.” In Web Search: Multidisciplinary Perspectives, edited by Amanda Spink and Michael Zimmer, 309-40. Berlin, Heidelberg: Springer-Verlag. DOI: https://doi. org/10.1007/978-3-540-75829-7_16.

Lewandowski, D. 2015. "Evaluating the Retrieval Effectiveness of Web Search Engines Using a Representative Query Sample." Journal of the Association for Information Science and Technology 66 (9): 1763-75. DOI: https://doi.org/10.1002/asi.23304. 
Lin, C., Y.-A. Huang, and R. Stockdale. 2011. "Developing a B2B Web Site Effectiveness Model for SMEs.” Internet Research 21 (3): 304-25. DOI: https://doi.org/10.1108/ 10662241111139327.

Lindič, J., M. Bavdaž, and H. Kovačič. 2012. "Higher Growth Through the Blue Ocean Strategy: Implications for Economic Policy." Research Policy 41 (5): 928-38. DOI: https://doi.org/10.1016/j.respol.2012.02.010.

Lundvall, B.-Å., and S. Borrás. 2005. "Science, Technology and Innovation Policy.” In The Oxford Handbook of Innovation, edited by Jan Fagerberg, David C. Mowery, and Richard R. Nelson: 599-631. Oxford University Press Oxford.

MacFeely, S. 2019. "Big Data and Official Statistics." In Big Data Governance and Perspectives in Knowledge Management, edited by Sheryl Kruger Strydom and Moses Strydom, 25-54. IGI Global. DOI: https://doi.org/10.4018/978-1-5225-7077-6.ch002. Mergel, I., R.K. Rethemeyer, and K. Isett. 2016. "Big Data in Public Affairs." Public Administration Review 76 (6): 928-37. DOI: https://doi.org/10.1111/puar.12625.

Mooney, R.J., and R. Bunescu. 2005. "Mining Knowledge from Text Using Information Extraction.” ACM SIGKDD Explorations Newsletter 7 (1): 3-10. DOI: https://doi.org/ 10.1145/1089815.1089817.

Munari, F., and L. Toschi. 2014. "Running Ahead in the Nanotechnology Gold Rush. Strategic Patenting in Emerging Technologies." Technological Forecasting and Social Change 83: 194-207. DOI: https://doi.org/10.1016/j.techfore.2013.07.002.

Nathan, M., A. Rosso, T. Gatten, P. Majmudar, and A. Mitchell. 2013. "Measuring the UK's Digital Economy With Big Data." National Institute of Economic and Social Research London. Available at: https://www.niesr.ac.uk/sites/default/files/publications/SI024_GI_NIESR_Google_Report12.pdf (accessed February 2020).

National Academies of Sciences, Engineering, and Medicine. 2018. "Sampling and Estimation." In Reengineering the Census Bureau's Annual Economic Surveys, edited by K.G. Abraham, C.F. Citro, G.D. White, and N.K. Kirkendall: 91-118. Washington, D.C.: National Academies Press. DOI: https://doi.org/10.17226/25098.

OECD, and the Royal Society. 2010. Symposium on Opportunities and Challenges in the Emerging Field of Synthetic Biology. OECD Publishing. DOI: https://doi.org/10.1787/ 9789264086265-en.

Oldham, P., S. Hall, and G. Burton. 2012. "Synthetic Biology: Mapping the Scientific Landscape.” Edited by J.A. Gilbert. PLoS ONE 7 (4): E34368. DOI: https://doi.org/ 10.1371/journal.pone.0034368.

Oostrom, L., A. Walker, B. Staats, M. Slootbeek-van Laar, S. Azurduy, and B. Rooijakkers. 2016. "Measuring the Internet Economy in the Netherlands: A Big Data Analysis." The Hague: Statistics Netherlands. Available at: https://www.nldigital.nl/wp-content/uploads/2016/10/measuring-the-internet-economy.pdf (accessed February 2020).

PCAST. 2005. "The National Nanotechnology Initiative at Five Years." Washington, D.C., U.S.A. Available at: https://www.nano.gov/sites/default/files/pub_resource/final_pcast_nano_report_for_web.pdf (accessed February 2019).

Pedregosa, F., G. Varoquaux, A. Gramfort, V.M.B. Thirion, O. Grisel, M.Blondel, et al. 2011. "Scikit-Learn: Machine Learning in Python." Journal of Machine Learning Research 12: 2825-30. Available at: https://www.jmlr.org/papers/volume12/pedregosa11a/pedregosa11a.pdf (accessed February 2019). 
Pew. 2018. "Internet/Broadband Fact Sheet.” Available at: http://www.pewinternet.org/ fact-sheet/internet-broadband/ (accessed February 2019).

Popp, D. 2016. "Economic Analysis of Scientific Publications and Implications for Energy Research and Development." Nature Energy 1 (4): 16020. DOI: https://doi.org/10.1038/ nenergy.2016.20.

Popp, D. 2017. "From Science to Technology: The Value of Knowledge from Different Energy Research Institutions.” Research Policy 46 (9): 1580-94. DOI: https://doi. org/10.1016/j.respol.2017.07.011.

Qi, X., and B.D. Davison. 2007. "Web Page Classification.” ACM Computing Surveys 41 (2): 1-31. DOI: https://doi.org/10.1145/1459352.1459357.

Raimbault, B., J.-P. Cointet, and P.-B. Joly. 2016. "Mapping the Emergence of Synthetic Biology.” Edited by Mark Isalan. PLOS ONE 11 (9): E0161522. DOI: https://doi.org/ 10.1371/journal.pone.0161522.

Rajaraman, A., and J.D. Ullman. 2011. Mining of Massive Datasets. Cambridge University Press.

Reimsbach-Kounatze, C. 2015. "The Proliferation of 'Big Data' And Implications for Official Statistics and Statistical Agencies: A Preliminary Analysis.” 245. OECD Digital Economy Papers. Paris. DOI: https://doi.org/10.1787/5js7t9wqzvg8-en.

Rothwell, R. 1989. "Small Firms, Innovation and Industrial Change." Small Business Economics 1 (1): 51-64. DOI: https://doi.org/10.1007/BF00389916.

Safavian, S.R., and D. Landgrebe. 1991. "A Survey of Decision Tree Classifier Methodology." IEEE Transactions on Systems, Man, and Cybernetics 21 (3): 660-74. DOI: https://doi.org/10.1109/21.97458.

Särndal, C.-E., B. Swensson, and J. Wretman. 2003. Model Assisted Survey Sampling. New York: Springer-Verlag.

Shapira, P., A. Gök, E. Klochikhin, and M. Sensier. 2013. "Probing 'Green’ Industry Enterprises in the UK: A New Identification Approach.” Technological Forecasting and Social Change. DOI: https://doi.org/10.1016/j.techfore.2013.10.023.

Sicilia, M.-A., E. García-Barriocanal, and S. Sánchez-Alonso. 2017. "Community Curation in Open Dataset Repositories: Insights from Zenodo." Procedia Computer Science 106: 54-60. DOI: https://doi.org/10.1016/j.procs.2017.03.009.

Simon, H.A. 1996. The Sciences of the Artificial. 3rd ed. Cambridge, MA: MIT Press.

Sullivan, I., A. DeHaven, and D. Mellor. 2019. "Open and Reproducible Research on Open Science Framework.” Current Protocols Essential Laboratory Techniques 18 (1). DOI: https://doi.org/10.1002/cpet.32.

Talan, D.M. 2016. "Opportunities and Challenges for Using Big Administrative Data." Available at: https://www.bls.gov/osmr/research-papers/2016/pdf/st160100.pdf (accessed February 2019).

Tambe, P. 2014. "Big Data Investment, Skills, and Firm Value." Management Science 60 (6): 1452-69. DOI: https://doi.org/10.1287/mnsc.2014.1899.

Teece, D.J., M. Peteraf, and S. Leih. 2016. "Dynamic Capabilities and Organizational Agility: Risk, Uncertainty, and Strategy in the Innovation Economy." California Management Review 58 (4): 13-35. DOI: https://doi.org/10.1525/cmr.2016.58.4.13.

Ten Bosch, O., D. Windmeijer, A. Van Delden, and G. Van Den Heuvel. 2018. "Web Scraping Meets Survey Design: Combining Forces.” In Big Data Meets Survey Science Conference, 
Barcelona, Spain. Available at: https://www.bigsurv18.org/conf18/uploads/73/61/ 20180820_BigSurv_WebscrapingMeetsSurveyDesign.pdf (accessed February 2020).

Toumey, C. 2009. "Plenty of Room, Plenty of History." Nature Nanotechnology 4 (12): 783-84. DOI: https://doi.org/10.1038/nnano.2009.357.

U.K. Office for National Statistics. 2020. "Business enterprise research and development, UK: 2019." Available at: https://www.ons.gov.uk/economy/governmentpublicsectorandtaxes/researchanddevelopmentexpenditure/bulletins/businessenterpriseresearchanddevelopment/2019 (accessed February 2020).

U.S. Census Bureau. 2020a. "About Annual Business Survey." Available at: https://www.census.gov/programs-surveys/abs/about.html (accessed March 2020).

U.S. Census Bureau. 2020b. “About this Survey.” Available at: https://www.census.gov/programs-surveys/abs/about.html.

U.S. Energy Information Administration. 2018. “Available Energy Explained.” Available at: https://www.eia.gov/energyexplained/renewable-sources/incentives.php (accessed February 2019).

U.S. Small Business Administration. 2018. "Frequently Asked Questions." Available at: https://www.sba.gov/sites/default/files/advocacy/Frequently-Asked-Questions-SmallBusiness-2018.pdf (accessed February 2019).

USPTO. 2019. "PatentsView." Available at: https://www.patentsview.org/download/(accessed March 2020).

USPTO. 2020. "US Patent Activity, CY 1790 to Present." Available at: https://www.uspto.gov/web/offices/ac/ido/oeip/taf/h_counts.htm (accessed March 2020).

Van Delden, A., D. Windmeijer, and O. Ten Bosch. 2019a. "Finding Enterprise Websites." In European Establishment Statistics Workshop. Bilbao, Spain. Available at: https://www.researchgate.net/profile/Arnout_Delden/publication/336995371_Finding_enterprise_websites/links/5dbebf29299bf1a47b0f5669/Finding-enterprise-websites.pdf (accessed February 2020).

Van Delden, A., D. Windmeijer, and O. Ten Bosch. 2019b. "Searching for Business Websites." Centraal Bureau Voor De Statistiek. Available at: https://www.cbs.nl//media/_pdf/2020/01/searching-for-business-websites.pdf (accessed February 2020).

Van Doren, D., S. Koenigstein, and T. Reiss. 2013. "The Development of Synthetic Biology: A Patent Analysis." Systems and Synthetic Biology 7 (4): 209-20. DOI: https://doi.org/10.1007/s11693-013-9121-7.

Wang, F., and L. Vaughan. 2014. "Firm Web Visibility and Its Business Value." Internet Research 24 (3): 292-312. DOI: https://doi.org/10.1108/IntR-01-2013-0016.

Williams, C.K.I., and C.E. Rasmussen. 2006. Gaussian Processes for Machine Learning. Cambridge, MA: MIT Press.

Young, L.J., M. Hyman, and B.R. Rater. 2018. "Exploring a Big Data Approach to Building a List Frame for Urban Agriculture: A Pilot Study in the City of Baltimore." Journal of Official Statistics 34 (2): 323-40. DOI: https://doi.org/10.2478/jos-2018-0015.

Received September 2019

Revised March 2020

Accepted September 2020 